\title{
STUDY ON EXPERIMENTAL DETERMINATION OF THE ELASTICITY MODULUS OF CASTED BASALT
}

\author{
Ilie Octavian POPP \\ "Lucian Blaga" University of Sibiu, Romania \\ e-mail: ilie.popp@ulbsibiu.ro
}

\begin{abstract}
Basalt is a material available in big quantities in nature. It has a low price and can be used in various domains. It can be relatively easily extracted from natural deposits and processed by means of melting. Melted and recrystallized basalt has demonstrated promising behavior with regards of its use in manufacturing, as reported in the literature.

This paper presents the results of an experimental study on the determination of the modulus of elasticity of molten and recrystallized basalt by the method of resistive electrical tensometry and to validate the result and by simulation using finite elements method. Testing methodology, experimental test, data records, data processing and resulting conclusions are presented in the paper.
\end{abstract}

KEYWORDS: materials, experimental study, modulus of elasticity of basalt

\section{Introduction}

One of the major issues of the contemporary world, in the context of the global crisis of raw materials and materials, is the saving of ferrous and non-ferrous metal, as well as of other deficient and expensive materials. Within this action, the concerns for introducing and extending the use of basalt, a material found in large quantities in nature, accessible and inexpensive are also included. Basalt is the most widespread material on the surface of the earth. It appears in all four major tectonic environments.

Basalt is a natural, hard, dense, dark brown to black volcanic rock originating at a depth of hundreds of kilometers beneath the earth and reaching the surface as molten magma. The simplicity of the manufacturing process reduces the production cost of basalt parts and fibers in industry. The quality and chemical composition of the basalt raw material have a major effect on the costs and properties of the parts and fibers made from this material and can lead broad range of application in industry, with different mechanical properties [1].

From the study of the scientific literature and other researches in the field, the following aspects can be remarks:

Known technologies allow the processing of basalt by $[2,3]$ :

- melting and recrystallization;

- sintering;
- basalt fibers.

By melting and recrystallization, the basalt improves its main chemical, physical and mechanical characteristics, of which we mention:

- exceptional abrasion resistance, which in most cases exceeds that of high alloy steels;

- very high resistance against acids (sulfuric acid, hydrochloric acid, other strong acids, except for hydrofluoric acid); stability to solutions of sodium hydroxide, potassium hydroxide and other bases;

- special dielectric properties;

- wear resistance by sliding;

- thermal and sound insulation (in the form of wool);

- successfully replaces high alloy steels and castings in the construction of some plants and machinery.

In addition to the advantages presented above, there are still several disadvantages:

- it has no plasticity;

- it doesn't withstand mechanical shocks very well;

- it doesn't resist to thermal shocks, the maximum temperature coefficient of resistance is 400-600 ${ }^{\circ} \mathrm{C}$.

The use of basalt products is justified and it is necessary to look for other areas and methods where there could be the possibility of using this material. Although basalt is a material known to specialists in the silicate industry and the construction industry, the 
same cannot be said about its use in the field of machine construction. The car construction industry has completely different characteristics than the ones found in constructions and that is why extensive research is required in order to highlight the characteristics of basalt, to exploit the advantages offered by it and to eliminate the disadvantages [4].

Therefore, the problem of basalt behavior to specific requests, in order to use it in the manufacture of the structural elements of the machines and equipments has not yet been addressed so this paper aims to make a necessary introduction in this direction. As a result, the elastic modulus and strength of basalt composites as material for machine parts must be evaluated carefully $[5,6]$.

\section{General topics}

In machine tool and equipment manufacturing industry, it is necessary to be chosen materials that withstand the demands that may arise in operation. For this, in first phase of design and calculation of dimensioning the structural elements, it is important to know the elastic characteristics of the materials.

Knowing the specific deformations of the material produced during a mechanical stress (axial, bending or twisting) in the elastic field and using the relationships of STAS 10290-86 (Metal testing. Tensile testing. Determination of the elastic characteristics [7]) the numerical values of the elasticity modules $\mathrm{E}$ and $\mathrm{G}$ can be determined. In addition, with the help of specific deformations the value of the cross-sectional contraction coefficient $v$ is determined.

For this determination, the method of resistive electrical tensometry was used and the experiments were carried out in the Materials Resistance laboratory of Engineering Faculty of Sibiu. The planning and conduct of these experimental researches were done in compliance with the current standards. Also, the methods of collecting and statistical processing of the experimental data are those recommended by the Romanian standards.

\section{Determination of the basalt elastic characteristics by the method of resistive electrical tensometry}

Resistive electrical tensometry is a method that allows measuring the specific deformations of the requested part with high precision. In order to determine the coefficient of transverse contraction on a normal flat specimen, two resistive electrical transducers are marked on the opposite sides: one along the axis and the other perpendicular or one rosette with two perpendicular translators. The electric transducers are connected in full deck using the bridge property to algebraically gather the variations of resistors of the transducers connected in the same arm or opposite arms and to algebraically decrease the variations of the resistances of the transducers connected in adjacent arms. The complete bridge assembly avoids the parasitic effects, the translator placed transversely on the specimen having the role of the compensation translator. Transducers with the same value for the voltage constant and the same value for the electrical resistance are chosen. The difference between the indication of the tensometric bridge circuit after loading the specimen and the indication of the bridge before loading the specimen represents the specific deformation read at the strain gauge bridge circuit.

The static constants of elasticity were determined on a number of 16 basalt specimens, of dimensions $1 \times b x h=16.6 \times 11.7 \times 240 \mathrm{~mm}$, on which four strain gauges TER1-TER4 linear type SGD6/120-LY13 were placed, (Fig. 1). The specimens were loaded for simple bending with forces having different numerical values (Table 1) and the tensometric bridge indications representing the specific deformations $(\varepsilon)$ were read.

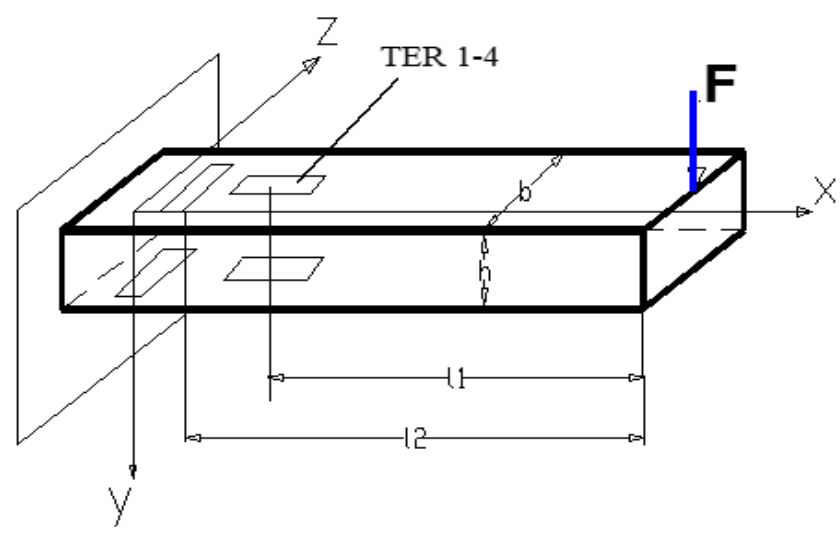

Fig. 1. The model of the basalt specimen 
The modulus of static longitudinal elasticity is determined by the relation [7]:

$$
E=\frac{6 l_{1} F}{b h^{2} \varepsilon_{x(z)}}\left[\mathrm{N} / \mathrm{m}^{2}\right]
$$

and the coefficient of the transverse contraction with the relation:

$$
v=-\frac{\varepsilon_{z}}{\varepsilon_{x}} * \frac{l_{1}}{l_{2}}
$$

where $l_{1}, l_{2}, b$, $h$ are the dimensions of the specimen and have the meaning in Fig. 1, F is the applied force, and $\varepsilon_{\mathrm{x}}$ and $\varepsilon_{\mathrm{z}}$ are the strain in the $\mathrm{x}$ and $\mathrm{z}$ directions, expressed in $\mu \mathrm{m} / \mathrm{m}$ on the scale of the measuring apparatus.

The transverse elasticity modulus determined statically, considering the molten basalt and recrystallized as an isotropic material, it is calculated with the relation:

$$
G=\frac{E}{2(1+v)}\left[\mathrm{N} / \mathrm{m}^{2}\right]
$$

The mean values obtained from experimental measurements performed on the casted basalt parts are shown in Table 1.

Table 1. The numerical values of the test

\begin{tabular}{|c|c|c|c|c||}
\hline $\mathbf{F}[\mathbf{N}]$ & $\mathbf{1 0}$ & $\mathbf{2 0}$ & $\mathbf{2 5}$ & $\mathbf{3 0}$ \\
\hline \hline$\varepsilon_{\mathrm{x} 1}[\mu \mathrm{m} / \mathrm{m}]$ & +27 & +58 & +72 & +102 \\
\hline$\varepsilon_{\mathrm{x} 2}[\mu \mathrm{m} / \mathrm{m}]$ & -30 & -58 & -82 & -102 \\
\hline$\varepsilon_{\mathrm{z} 3}[\mu \mathrm{m} / \mathrm{m}]$ & -11 & -20 & -32 & -29 \\
\hline$\varepsilon_{\mathrm{Z} 4}[\mu \mathrm{m} / \mathrm{m}]$ & +11 & +19 & +27 & +29 \\
\hline $\mathrm{E}_{1}\left[10^{10} \mathrm{~N} / \mathrm{m}^{2}\right]$ & 9.530 & 8.872 & 8.652 & 8.046 \\
\hline $\mathrm{E}_{2}\left[10^{10} \mathrm{~N} / \mathrm{m}^{2}\right]$ & 8.577 & 8.872 & 8.597 & 8.046 \\
\hline $\mathrm{E}_{\mathrm{med}}\left[10^{10} \mathrm{~N} / \mathrm{m}^{2}\right]$ & 9.053 & 8.872 & 8.124 & 8.046 \\
\hline$v^{\prime}$ & 0.354 & 0.327 & 0.386 & 0.247 \\
\hline$v^{\prime \prime}$ & 0.318 & 0.327 & 0.286 & 0.247 \\
\hline$v_{\mathrm{med}}$ & 0.336 & 0.327 & 0.336 & 0.247 \\
\hline $\begin{array}{l}\mathrm{E}=(8.523 \pm 0.512) \\
v=0.333 \pm 0.0052 \\
\mathrm{G}=(3.196 \pm 0.254) 10^{10} \mathrm{~N} / \mathrm{m}^{2}\end{array}$ & $\mathrm{~N} / \mathrm{m}^{2}$ & & & \\
\hline \hline
\end{tabular}

The experimental data obtained from the tests was analyzed using Microsoft EXCEL. Statistical processing of the measurement results (the values of deformations) was done considering a significance threshold $\alpha=0.05$. The Cochran test was applied to determine the homogeneity of the dispersion and the Student test to eliminate the insignificant effects. Interpreting the data obtained from the measurements and using the relationships (1), (2) and (3), the values of the static elasticity modulus E, the coefficient of the transverse contraction $v$ and the transverse elasticity modulus $\mathrm{G}$, were determined as presented in Table 1.
Behavior tendency of basalt, determined by the series of experimental data presented, was highlighted using Microsoft EXCEL software, through the linear regression method. It draws a line through a series of values resulting from measurements using the least squares method. The linear regression equation $(\mathrm{y}=$ $\mathrm{ax}+\mathrm{b}$ ) and the value of $\mathrm{R} 2$ are calculated automatically by the program and are displayed in the diagram from Fig. 2.

The experimental values obtained for the elastic constants of the basalt (E, v, G - Table 1) are useful in knowing the most accurate behavior as a base material or a substitute material in different mechanical constructions. We observe an almost 


\section{THE ANNALS OF “DUNAREA DE JOS” UNIVERSITY OF GALATI \\ FASCICLE IX. METALLURGY AND MATERIALS SCIENCE \\ $\mathrm{N}^{\circ} .4$ - 2020, ISSN 2668-4748; e-ISSN 2668-4756 \\ Article DOI: https://doi.org/10.35219/mms.2020.4.08}

linear behavior of the basalt in the analyzed elastic

inhomogeneous of the material structure from range (Fig. 2). The dispersion obtained is due to the different batches and due to measurement errors.

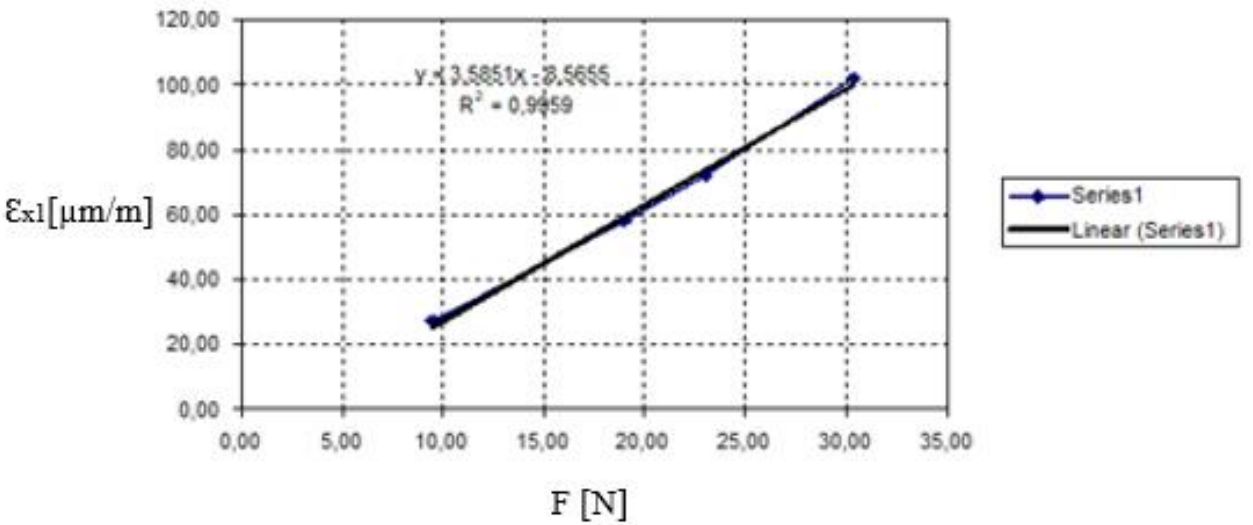

Fig. 2. Behavior tendency of basalt given by experimental results

\section{FEM of determined elasticity modulus}

In order to further validate the experimental data obtained from the tested parts, numerical investigation was performed and a basalt bar was modeled. The simulation of the test was performed through finite element method with the help of Abaqus software package. The analysis of the process followed an implicit scheme in order to obtain results as precise as possible. The basalt part is meshed with the help of C3D8R element with the dimension of 2 mm, thus obtaining 5760 elements on this specimen. The specimen is fixed at one end and on the other forces are applied in the form of 4 pressures in different steps like in Fig. 3a. For the analysis to be carried out the basalt specimen was modeled using the elasticity modulus determined experimentally and Poisson coefficient which was calculated as 0.333 .

After running the analysis, when applying the forces of $10 \mathrm{~N}, 20 \mathrm{~N}, 25 \mathrm{~N}$ and $30 \mathrm{~N}$, the maximum displacement values and the maximum von Mises stresses, presented in Fig. 4 are obtained.

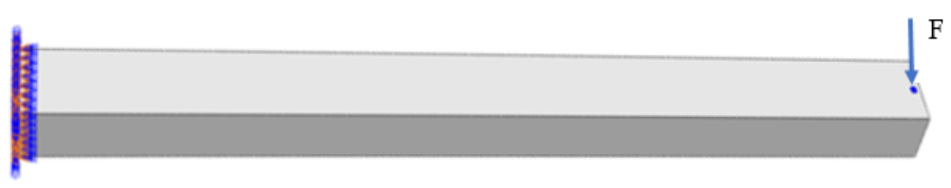

Fig. 3. Basalt specimen modeled in Abaqus
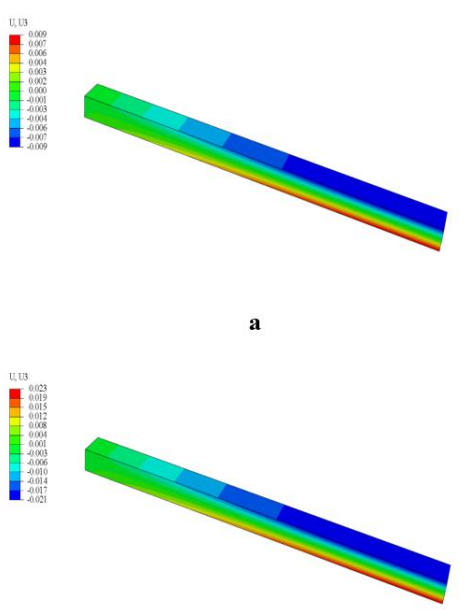

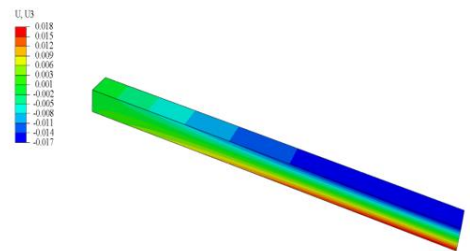

b

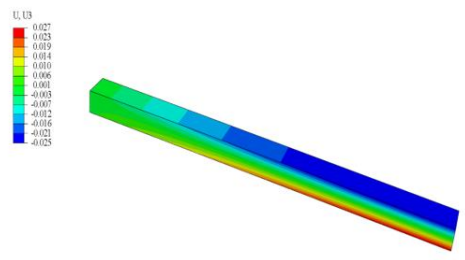

Fig. 4. Displacement of U3 (axial direction) when a force of $10 \mathrm{~N}, 20 \mathrm{~N}, 25 \mathrm{~N}$ and $30 \mathrm{~N}$ is applied 


\section{THE ANNALS OF “DUNAREA DE JOS” UNIVERSITY OF GALATI \\ FASCICLE IX. METALLURGY AND MATERIALS SCIENCE \\ $\mathrm{N}^{\circ} .4$ - 2020, ISSN 2668-4748; e-ISSN 2668-4756 \\ Article DOI: https://doi.org/10.35219/mms.2020.4.08}

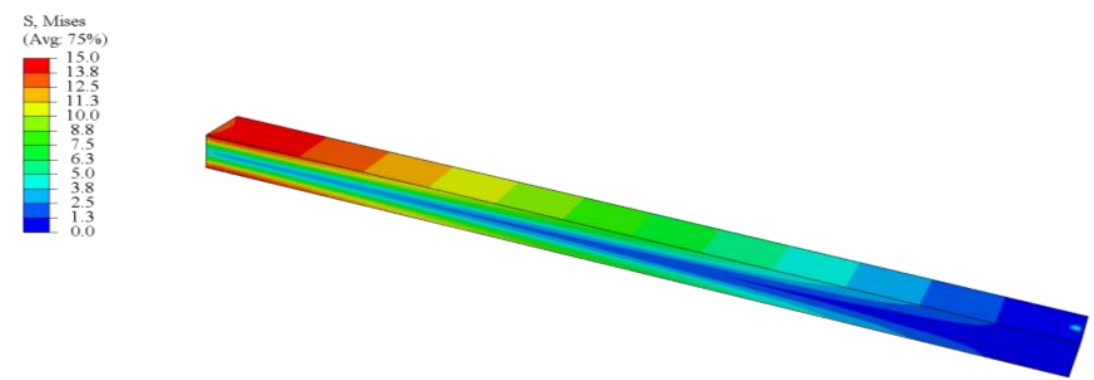

Fig. 5. The von Mises stresses when a force of $30 \mathrm{~N}$ is applied

A comparison of the values obtained experimentally and through finite element analysis can be seen in Table 2.

Table 2. Comparison between the values of displacement on axial direction obtained experimentally and through numerical analysis

\begin{tabular}{|c|c|c|}
\hline $\begin{array}{c}\text { Forces } \\
{[\mathbf{N}]}\end{array}$ & $\begin{array}{c}\text { Displacements } \\
\text { obtained } \\
\text { experimentally } \\
{[\boldsymbol{\mu m}]}\end{array}$ & $\begin{array}{c}\text { Displacements } \\
\text { obtained } \\
\text { through FEM } \\
{[\boldsymbol{\mu} \mathbf{m}]}\end{array}$ \\
\hline 10 & 6 & 9 \\
\hline 20 & 14 & 18 \\
\hline 25 & 17 & 23 \\
\hline 30 & 24 & 27 \\
\hline
\end{tabular}

\section{Conclusions}

The elastic deformations of the loaded elements of machine tools (mullion, sleepers, tines, tables, housings, etc.) must be appreciated in terms of their influence on the precision of the manufacturing of the workpiece. The deformations result from the action of the cutting forces, the own weight of the loaded elements, the weight of the semi-finished product, the clamping forces and sometimes even the forces of moving inertial masses.

The value of the static elasticity modulus of the casted basalt was determined, with the help of bartype samples subjected to bending through resistive electrical tensometry method. These values obtained from the presented experiments, were taken into account as material characteristics, when modeling the static behavior of the basalt through the method of the finite elements.

Table 2 shows that the values of displacements of the basalt specimen determined through finite element analysis method are approximately with the values obtained experimentally and this is due to the fact that in numerical investigation software, Abaqus, the elasticity modulus $\mathrm{E}$ was taken $8.523 \times 10^{10}$ $\left[\mathrm{N} / \mathrm{m}^{2}\right]$.

\section{References}

[1]. Möhring H.-C., Brecher C., Abele E., Fleischer J., Bleicher F., Materials in machine tool structures, CIRP Annals Manufacturing Technology, 64 (2), p. 725-748, 2015.

[2]. Gornic C., Bazaltul materie primã pentru piesele destinate masinilor unelte, ICSITMU - Titan Bucuresti, 1989.

[3]. Ducatti V., Lintz R., Santos J., Comparative Study with Alternative Materials for Manufacture of Machine Tool Structure, International RILEM Conference on the Use of Recycled Materials in Building and Structures, p. 925-934, 2004.

[4]. Kepczak N., Pawlowski W., Application of Mineral Casting for Machine Tools Beds, Mechanics and Mechanical Engineering, 17(4), p. 285-289, 2013.

[5]. Popp I. O., Consideration regarding the properties and behaviour of basalt used in machine building, in Proceedings, $\mathrm{p}$. 127-130, First international Conference on Materials and Manufacturing Tehnologies, MATEHN' 94, Cluj-Napoca, 1994.

[6]. Popp I. O., Contributii la cercetarea comportarii bazaltului supus unor solicitari specifice masinilor unelte, Teza de doctorat, "Lucian Blaga" University of Sibiu, 1999.

[7]. Mocanu D. R., et al., Incercarile materialelor, vol. I, II, Editura Tehnica, București, 1982. 